\title{
HRM Process Advantage for Firm Performance
}

\author{
R. Sridhar ${ }^{1,2, *}$ \\ ${ }^{1}$ XLRI, Jamshedpur, Jharkhand, India \\ ${ }^{2}$ ITC Limited, Kolkata, India \\ *Correspondence: ITC Limited, Corporate Human Resources, Virginia House, 37, J.L. Nehru Road, Kolkata 700071, \\ India. Tel: 91-983-105-5312. E-mail: r.sridhar@itc.in
}

Received: April 13, $2015 \quad$ Accepted: May 7, $2015 \quad$ Online Published: July 7, 2015

doi:10.5430/mos.v2n3p17 URL: http://dx.doi.org/10.5430/mos.v2n3p17

\begin{abstract}
To date, most research focused on the possibility of a link between HRM and Organizational Performance has tended to home in on the content of HRM policies, practices, and strategies, and explore which of them make a difference to organizational outcomes. The presupposition in such research is that "what is done is more critical than how it is done".

In this study, based on social context and social influence theories, the HRM-Organizational Performance relationship has been examined from an HRM process vantage point. It was proposed that employees' perceptions of organizational level characteristics of the HRM process would reflect the "strength" of HRM. This strength would influence the formation of an organizational HRM climate for empowerment, commitment and citizenship. Further, HRM process strength would influence employee performance and voluntary employee turnover. The construct of HRM process strength was validated using Structural Equation Modeling analysis. Regression and Hierarchical Linear Modeling Analyses showed that HRM process strength influences employees' attitudes and behaviors, their performance, and voluntary employee turnover.

Keywords: Social context theory, Social influence theory, Climate, HRM process strength, Psychological empowerment, Employee commitment, Organizational citizenship behavior, Organizational performance
\end{abstract}

\section{Introduction}

The field of Human Resource Management (HRM) and, by extension, the Human Resource (HR) function face an endless battle to justify both their role in as well as their contribution to organizations. Intrinsic to this challenge is the difficulty in measuring the impact of people-related investments - a major stumbling block which constrains those responsible for these decisions. During upturns, firms can easily justify expenditure on training, staffing, rewards and employee involvement practices, but during downturns, these are the first to succumb to budgetary cutbacks (Wright, Dunford \& Snell, 2001), largely as a result of the inability to draw a clear line connecting HRM investments to business results (Legge, 1995).

For some time now, HR scholars have been suggesting ways to remedy the situation and equip HRM to assert its role in contributing to organizational performance. One recommendation, acknowledged as a universal best practice, is to identify and recruit strong performers, provide them with the abilities and confidence to work effectively, monitor their progress towards performance targets, and reward them well for meeting or exceeding these targets (Paauwe \& Boselie, 2005).

Another set of recommendations, termed strategic HRM, (e.g., Huselid, 1995; Wright \& Snell, 1998), lays emphasis on the total system of HRM practices. It is the system in its totality that should be inherently strong, rather than individual practices; the system of practices should align vertically with business strategy, and the individual practices within the system should be interrelated and internally consistent.

For managers, the body of theory and research focusing on establishing a link between HRM and organizational performance has been overwhelming to say the least. Yet the picture lacks clarity. Despite having quality people and superior systems, organizations often fail to deliver on their intent. They readily admit that the cause of failure tends 
to lie in their inability to implement systems in a consistent manner. Much writing about HRM at the strategic level has tended to assume that the mere existence of HRM policies and a people strategy, i.e. the vertical and horizontal dimensions are sufficient to ensure action. But, fundamental to the question of whether an organization is delivering in the area of people management is whether these policies and strategies are effectively being translated into action (Gratton \& Truss, 2003). Another critical question is how do we measure the implementation of HRM policies and their effects on organizational performance?

In recent times, calls have been made for a greater understanding of HRM implementation process issues (e.g., Ferris, Hochwarter, Buckley, Harrell-Cook \& Frink, 1999; Truss, 2001; Gratton \& Truss, 2003; Bowen \& Ostroff, 2004), particularly since the consensus is that HRM performance literature has yielded inconclusive results. Kim and Mauborgne (1997) had discussed the principles of fair process: seeking engagement; providing explanation; and establishing expectation clarity, as one way of building good execution into the HRM implementation process. Bowen and Ostroff (2004) proposed examining the ways in which organizations implement HRM policies and practices - which they term HRM system processes. In addition to fairness, they wanted "distinctiveness" and "consistency" to be considered as key implementation features necessary for creating a strong HRM "climate". Empirical studies establish that such a strong climate would enable psychological empowerment, employee commitment and citizenship behavior.

Regarding the measurement of the HRM implementation process, scholars suggest evaluating employee perceptions of HRM systems. These perceptions would reflect the extent to which employees consider HRM to be appropriately embedded in a firm's management system and to help them solve real business problems. The argument is that HRM systems should not only demonstrate their value in motivating and enabling employees to perform their jobs but that employees should perceive they do so. Their perceptions should thus stimulate an emerged and implemented form of engagement with the strategic factors that the organization considers important, and as they are reflected in the actual work of employees (Ferris, et al., 1999; Nishii \& Wright, 2007).

\section{Organizational Climate and Behavior}

What determines the way individuals behave - nature or nurture? Kurt Lewin's (1951), position in this long-standing debate is that behavior is a function of both the person and the environment. However, psychologists have been preoccupied with developing a technology of behavior prediction that depends almost entirely on individual differences, relying heavily on items of biographical history and measures of ability, attitude and personality. Yet, they find it difficult to predict how an individual's behavior will vary from one situation to another over a period of time (Frederiksen, 1972). The problem could be addressed by employing a completely different class of predictor variables, i.e. situational variables.

We could investigate person-situation interactions better and predict behavior more accurately by grouping situations based on their tendency to elicit similar behaviors. Mischel (1973) made the point that the "conditions" of situational variables of the environment provide individuals with information, which influences the person variables, and thereby affects thought and behavior under those conditions. Situations thus affect behavior insofar as they influence phenomena such as an individual's comprehension, expectancies, and responses.

One such situational variable, according to Kopelman, Brief and Guzzo (1990), is an organization's particular set of HRM practices which serves as an important factor in determining its climate or situation. They define climate as meaningful interpretations of a work environment by the people in it. The interpretations are naturally unique to different individuals in some respects, yet common environmental conditions exist, and individuals use them in their construction of an organization's climate.

Organizations implement various HRM practices to create the desired organizational climate and shape it towards a focal outcome. For example, if the focus is on raising productivity, some of the more widespread practices used include financial incentives; feedback; goal setting; systematic selection and placement; training and development; participation in decision making; work redesign; flexible work schedules; organizational development; and changes in organizational structure. Implementing these practices is likely to produce changes in one or more dimensions of the organizational climate in terms of productivity, such as goal emphasis, means emphasis, reward orientation, task support, and socio-emotional support.

Recently, the notion of strong or weak climates has begun to emerge. Its focus is on the extent to which employees interpret a situation in similar terms, thereby lowering the variance in perceptions about the situation (Bowen \& Ostroff, 2004). Researchers have found that strong "collective" climates, i.e. climates based on individuals' shared 
perceptual agreement, affect various work outcomes. Collective climates serve as frames of reference that shape members' attitudes and behaviors, and influence outcomes like satisfaction, performance, and perceived leadership style (Jackofsky \& Slocum, 1988).

Information exchange that is adequate and clear helps employees to understand the work situation better and function more effectively. Attribution theory has contributed significantly in determining features to be incorporated when designing systems which should enable employees to receive and interpret information uniformly (Fiske \& Taylor, 1991). Kelley (1973) defines attribution as one concerned with how people make causal explanations - how they answer questions beginning with "why?" The theory deals with the information they use in making causal inferences and answering causal questions. The central question in attribution theory is how does a person know that his/her perceptions, judgments and evaluations are correct or true? A person will know that his/her response to a particular stimulus is a valid one if the response is associated distinctively with the stimulus; if the response is similar to those made by others to the same stimulus, i.e. there is consensus; if the response is consistent over time on successive exposures to the stimulus and as the person interacts with it by means of different sensory and perceptual modalities. These three criteria of validity - distinctiveness, consensus and consistency - suggest a means of indexing an individual's level of information regarding any portion of his/her external world.

We need to consider two interrelated features of an HRM system - content and process. The policies and practices meant to achieve organizational goals such as innovation and productivity constitute the content of an HRM system (e.g., Klein \& Sorra, 1996). An organization's strategic goals drive the content of its HRM system and there are a number of different models detailing appropriate HRM practices for different organizational strategies (e.g., Miles \& Snow, 1984; Schuler \& Jackson, 1987)

By process, we mean the design and implementation of an effective HRM system. The process design helps to create "strong situations" in the form of shared meaning about the content, in turn leading to superior organizational performance. Bowen and Ostroff (2004) assert that HRM content and process require to be effectively integrated in prescriptive models that link strategic HRM to firm performance. There is plenty of literature regarding the content of HRM systems - specific HRM policies and practices that help build employee skills and enhance motivation to achieve particular outcomes (e.g., Delbecq \& Mills, 1985; Schneider, 1990). However, in terms of process, the social constructions that employees make of their interactions with HRM across practices and time have received relatively less attention.

Bowen and Ostroff (2004), using Mischel's (1973) construct of situational strength, and Kelley's (1973) attribution theory model, propose that when the process of implementing an HRM system is perceived to be high in distinctiveness, consistency, and consensus, it will create a strong situation. Using literature on message-based persuasion and social influence, they elucidate nine features of the HRM process that build in these three attributes, thereby creating a strong influence situation in which employees share constructions of the situation.

\section{Features of HRM System Process}

As proposed by Bowen and Ostroff (2004), these nine features of the HRM process comprise the following: (i) Visibility, (ii) Understandability, (iii) Legitimacy of Authority, and (iv) Relevance which fosters Distinctiveness; (v) Instrumentality, (vi) Validity, and (vii) Consistent HRM Messages which contribute to Consistency; (viii) Agreement among Principal HRM Decision Makers, and (ix) Fairness which enable Consensus.

\section{Distinctiveness}

Distinctiveness of a situation generally refers to features that allow it to stand out in the environment, thereby capturing attention and arousing interest. The field of marketing provides useful pointers on achieving distinctiveness through message-based persuasion. The characteristics usually associated with distinctiveness are visibility, understandability, legitimacy and relevance.

Visibility of HRM practices refers to the degree to which these practices are salient and readily observable. For example, if performance or pay criteria are transparent, this will create a strong situation in which everyone has shared constructions of the situation, and has uniform expectations regarding the most appropriate response pattern and available incentives.

In terms of understandability, HRM practice content that is clear, unambiguous and easily comprehensible enables all employees to develop a shared understanding of the content in intended ways. The more ambiguous or unclear the situational stimulus, the more likely are there to be multiple categorizations by employees, and individual differences 
in person variables would exert significant effects. The function of understanding is the ability to produce an effect. Simplicity is, therefore, a virtue when it comes to the design of HRM practice content.

Barnard (1938) argues that organizations are essentially cooperative systems which integrate the contributions of their individual participants. Implicit in this formulation is the idea that participants should feel motivated to contribute towards a common purpose. While attempting to reconcile the imposition of goals from above and contribution of compliance from below, leaders may invoke authority, but fail to gain compliance. This is because authority depends on validation from the respondents; the decision, as to whether or not an order has authority, lies with the person receiving the order and not with "persons of authority" or those who issue these orders. Employees consider HRM systems to be legitimate when the HRM function in the firm receives significant investments and visible top management support. This enables the function to be perceived as credible and having the necessary authority to make people related decisions.

Relevance in terms of the HRM system refers to defining the situation in such a way that individuals perceive the situation as relevant to goals that are important to them. There should also be clarity about what behaviors are required and suited to such goal attainment. Equally important is that influencing organizational agents must have and use both personal capabilities and legitimate authority to influence the achievement of these goals. The HRM system should seek alignment or congruence of organizational goals with individual goals for the system to be relevant to individuals. Only then will individuals be motivated to work towards achieving organizational goals and in doing so also fulfill their personal needs. Goal congruence is, therefore, an important ingredient for achieving relevance. Specifically, goal congruence between hierarchical levels (supervisor-subordinate) and within a level (peer-to-peer) relate positively to job satisfaction and organizational commitment, and negatively to intention to quit. Additionally, relevance and legitimacy of authority go hand-in-hand in linking cognitions of work environments to affect and, ultimately, to behavior.

\section{Consistency}

While the four characteristics associated with distinctiveness help draw attention to the HRM situation, thereby increasing the probability that employees receive and interpret the HRM message uniformly, it is unlikely that distinctiveness alone is sufficient for employees to view the situation uniformly. This is where consistency comes into play. Kelley's (1973) concept of consistency introduces notions such as attributional principles of causation and instrumentalities. Consistency generally refers to establishing an effect over time and modalities, whereby the effect occurs each time the entity is present, regardless of the form of interaction. The features that establish consistency over time, people, and contexts are instrumentality, validity and consistency of messages.

Vroom's (1964) expectancy theory argues that the strength of a tendency to act in a certain way depends on the strength of the expectation that the act will lead to a given outcome and on the attractiveness of that outcome to the individual. In the HRM context, this refers to establishing an unambiguous perceived cause-effect relationship with reference to the desired content-focused behaviors and associated employee consequences. Consistent repetition over time shapes instrumentalities. The ability of HRM staff and line managers to influence instrumentality attributions largely depends on the extent to which they have the resources and power to link outcomes to behavior or performance on a consistent and timely basis.

Employees can make valid attributions about HRM systems only when they experience congruence between precept and practice (Fiske \& Taylor, 1991). They can only respond to what HRM practices actually do. Hence, establishing a relationship between HRM and firm performance necessitates the demonstration of a link between operationalized HRM programs, processes and techniques, and firm performance. If the gap between intent and reality is wide, the link could be perceived to be less than valid, even spurious. When the gap is very wide, employees are likely to develop their own idiosyncratic interpretations.

There are three major dimensions in ensuring consistency of messages. To begin with, since organizational culture serves as an antecedent to HRM system content and process design (e.g., Kopelman et al., 1990), the espoused goals and values of senior management should resonate in employees' perceptions of HRM practices. Inconsistency arises when there is a difference between espoused and inferred goals and values. Another requirement for HRM messages to be consistent is that HRM practices should be internally aligned. Numerous scholars have highlighted the importance of designing an HRM system with practices that fit together as a whole to achieve the organization's goals (e.g., Wright \& Snell, 1991; Wright \& McMahan, 1992; Wright, McMahan \& McWilliams, 1994; Delery \& Doty, 1996; Becker \& Gerhart, 1996). A high performance situation is more likely to result when individual HRM practices are aligned to one another. Such an aligned HRM system is better placed to seek and reward appropriate employee behaviors (e.g., Ulrich \& Lake, 1991; Wright et al., 1994). 
A third dimension is stability over time. Rousseau and Wade-Benzoni, (1994) find that in organizations where practices have been operational over a substantial period of time, there is a higher degree of consensus among employees in terms of what is expected of them and in return, their own expectations of the organization. Further, extensive sensemaking and shared understanding emerge when sensemaking processes are highly "animated" (Maitlis, 2005). A central characteristic of this animation is an intense flow of information and sharing among stakeholder groups. Another characteristic is the continuous rhythm of these processes: sensemaking and sharing around issues remain active over an extended period.

\section{Consensus}

The third feature that enables strong HRM situations is consensus. According to Bowen and Ostroff (2004), Consensus comes about when there is agreement among principal HRM decision makers, and when employees perceive the HRM system to be fair. Consistency and consensus are related yet distinct. When HRM practices are implemented consistently, consensus is high. Low consensus, on the other hand, leads to HRM practices being implemented inconsistently. Strong agreement among decision makers on a message increases the visibility, relevance and consistency of the message and individuals find it easier to reach consensus among them. Disagreement, however, distorts the message and leads to inconsistency. Further, individuals find it difficult to make proper attributions of cause-effect relationships (Fiske \& Taylor, 1991).

A vast body of literature indicates that fairness or justice is an important motivator for people. When individuals perceive a lack of fairness, their morale declines, they are more likely to quit, and may even react adversely. Fair treatment, in contrast, breeds commitment, enhances intentions to stay on, and promotes helpful citizenship behaviors that go beyond the call of formal duty (Folger \& Cropanzano, 1998). In organizations, justice is related to the rules and social norms governing the distribution of outcomes (e.g., rewards and punishments); the procedures used for making such distribution decisions (as well as other types of decisions); the interpersonal treatment of people; and the sharing of information with people. Though justice could be understood in a philosophical sense (i.e., the extent to which a given action, outcome, or circumstance is in alignment with a certain ethical paradigm), Folger and Cropanzano (1998) prefer justice to be understood phenomenologically, i.e.an act is "just" because someone thinks it is just and responds accordingly.

Research indicates that HRM's perceived fairness affects how employees view HRM activity as well as the capability of the HRM system to influence employee attitudes and behaviors. For example, Colquitt, Noe and Jackson (2002) find a beneficial relationship between the procedural justice climate and team effectiveness, as operationalized by team performance and absenteeism. Teams with favorable climate levels tend to perform better and engage in less absenteeism. Bowen, Gilliland and Folger (1999) find HRM practices (e.g., hiring, performance appraisal and rewards) that honor the principles of justice enable employees to display altruism, courtesy, sportsmanship, conscientiousness, and civic virtue. This in turn helps customers to perceive the service provided to them as "fair" and honoring "justice principles" in service delivery and service recovery. HRM practices that lead to positive employee perceptions of procedural and interactional justice increase the transparency of these distribution rules and, by so doing, increase the likelihood of consensus about the event-effect relationship (Bowen \& Ostroff, 2004).

Embedding these nine process features of strength in the implementation of HRM systems generates several positive consequences. They are more likely to promote collective perceptions and, in combination with appropriate and relevant content, lead to the emergence of a strong organizational climate - specifically a climate for service, quality, innovation, etc. The strength of the HRM system process will foster the emergence of an organizational climate (collective perceptions) from psychological climates (individual-level perceptions).

In a strong situation, employees' perceptions of the meaning of the situation will show little variability and will reflect a common desired content (e.g., Mischel, 1973; Kelley, 1973; James, James \& Ashe, 1990). Concomitantly, the organizational climate will display a significant association with employee attitudes and behaviors. This occurs because a strong HRM system process fosters higher consensus among employees about mutual expectations responsibilities, behaviors, incentives and rewards. Such a shared situational perception supports processes of social influence that lead to intended collective sensemaking. Therefore, an HRM system process high in distinctiveness, consistency and consensus, leads to the development of an intended organizational climate by establishing greater clarity in employees about HRM system content and helps them to identify similar cause-effect linkages. A weak situation, however, will generate messages that are ambiguous and subject to individual interpretation which could lead to variability and/or unintended sensemaking (Bowen \& Ostroff, 2004). The inherent ambiguity in such weak situations will cause psychological climate perceptions to be significantly associated with individual attitudes and 
behaviors (e.g., Mischel, 1973; Kelley, 1973). Alternatively, it may cause employees to interact and consult with one another to reduce the uncertainty and develop shared interpretations (e.g., Fiske \& Taylor, 1991; Drazin, Glynn \& Kazanjian, 1999). The collective interpretation that they arrive at could be strong, but often does not match what the organization intended, leading to conflicts, low productivity or poor effectiveness (Bowen \& Ostroff, 2004).

The nine features of HRM process implementation help create a strong, collective HRM climate, which, this paper argues, would enhance HRM effectiveness in terms of employee attitude formation, change and employee performance.

\section{Features of HRM System Process - Empirical Studies}

In what is probably the first study to empirically validate Bowen and Ostroff's (2004), conceptual model, Dorenbosch, Reuver and Sanders (2006) derived results that partially support the idea that HR-Line consensus on the HRM message and legitimacy of the message explains a proportion of the variability of the employee affective commitment strength construct at the department level. Pereira and Gomes (2012) explored the relationships between HRM strength, leadership, organizational climate and performance. The results of their study suggest that when HRM practices demonstrate little distinctiveness, consistency and consensus, they tend to foster weaker organizational "situations". It was also observed that at the HRM strength level, employees most noticeably agree on the dimensions centered on legitimacy, consistency of HR messages and agreement among principal HR decision makers, in some ways corroborating the earlier study.

A third study by Li, Frenkel and Sanders (2011) involving employees of three Chinese five-star hotels associated the three metafeatures of distinctiveness, consistency and consensus with high performance HRM practices related to training, internal promotion, employee participation, results-oriented pay, and job security, and measured their contribution to employees' work satisfaction, vigor and intention to quit. More "distinctive" HRM practices were found to contribute significantly to employees' work satisfaction and vigor, and reduced intention to quit. Consensus showed no significant effect and, contrary to expectations, a positive relationship was found between consistency and intention to quit. This anomaly has been explained as cultural - the Chinese perceive social relationships to be more important than formal rules in management decision making, thus for them, consistency in HRM practices has little bearing on intention to quit.

In a series of four studies intended to develop and validate a measure of the strength of the HRM system, Coelho, Cunha, Gomes and Correia (2012) again found that of the three metafeatures, distinctiveness emerged as the most salient. This finding was found to be valid whether one or more HR practices were considered as reference.

The author's study, conducted in 2007 in India, establishes the salience of all the three metafeatures of HRM process strength. Modeled on Bacharach's (1989) framework of theoretical social scientific enquiry, the framework examines the relationships between constructs, theory and the research process by proposing several links. The first link represents construct validity, i.e., the relationships between constructs and the operationalized measures of those constructs. The constructs considered in the study were the three HRM process strength metafeatures, four employee attitudes and behaviors (psychological empowerment, value commitment, continuance commitment, and organizational citizenship behavior), and organizational performance measures (quality and efficiency of employee work performance, and voluntary employee turnover). The constructs of psychological empowerment (Spreitzer, 1995), value commitment and continuance commitment (Fenton-O'Creevy, Winfrow, Lydka \& Morris, 1997), and organizational citizenship behavior (Dyne, Graham \& Dienesch, 1994) are already brightly lit by prior research. Those of employee performance and employee turnover are equally well established. The primary task, therefore, was to demonstrate construct validity of the three HRM process strength metafeatures of distinctiveness, consistency and consensus, and their operationalized measures.

Hypothesis 1:

There are three distinct metafeatures of HRM process strength (distinctiveness, consistency and consensus), each of which contributes to the overall construct of HRM process strength.

The second link represents the theoretically specified relationships between the constructs of interest. The hypotheses formulated in the study specify the relationships between the HRM process strength metafeatures, employee attitudes and behaviors, employee performance and employee turnover.

Hypothesis 2:

HRM process strength will be positively related to psychological empowerment.

Hypothesis 3 (a): 
HRM process strength will be positively related to value commitment.

Hypothesis 3 (b):

HRM process strength will be positively related to continuance commitment.

Hypothesis 4:

HRM process strength will be positively related to organizational citizenship behavior.

Hypothesis 5 (a):

HRM process strength will be positively related to the quality and efficiency of employees' work performance.

Hypothesis 5 (b):

HRM process strength will be negatively related to voluntary employee turnover.

The study included hypotheses that specified the relationships between the four employee attitudes and behaviors already mentioned and employee performance as well as voluntary employee turnover. However, these have been excluded from this paper as prior research has already established these relationships quite strongly.

The third link represents the empirically observed relationships between the respective measures of the constructs. The details of this study that are to follow shall highlight the observed relationships between HRM process strength on the one hand and employee attitudes and behavior, employee performance and employee turnover on the other. The relationships among constructs, theory, and research process in this study, are represented in Figure 1.

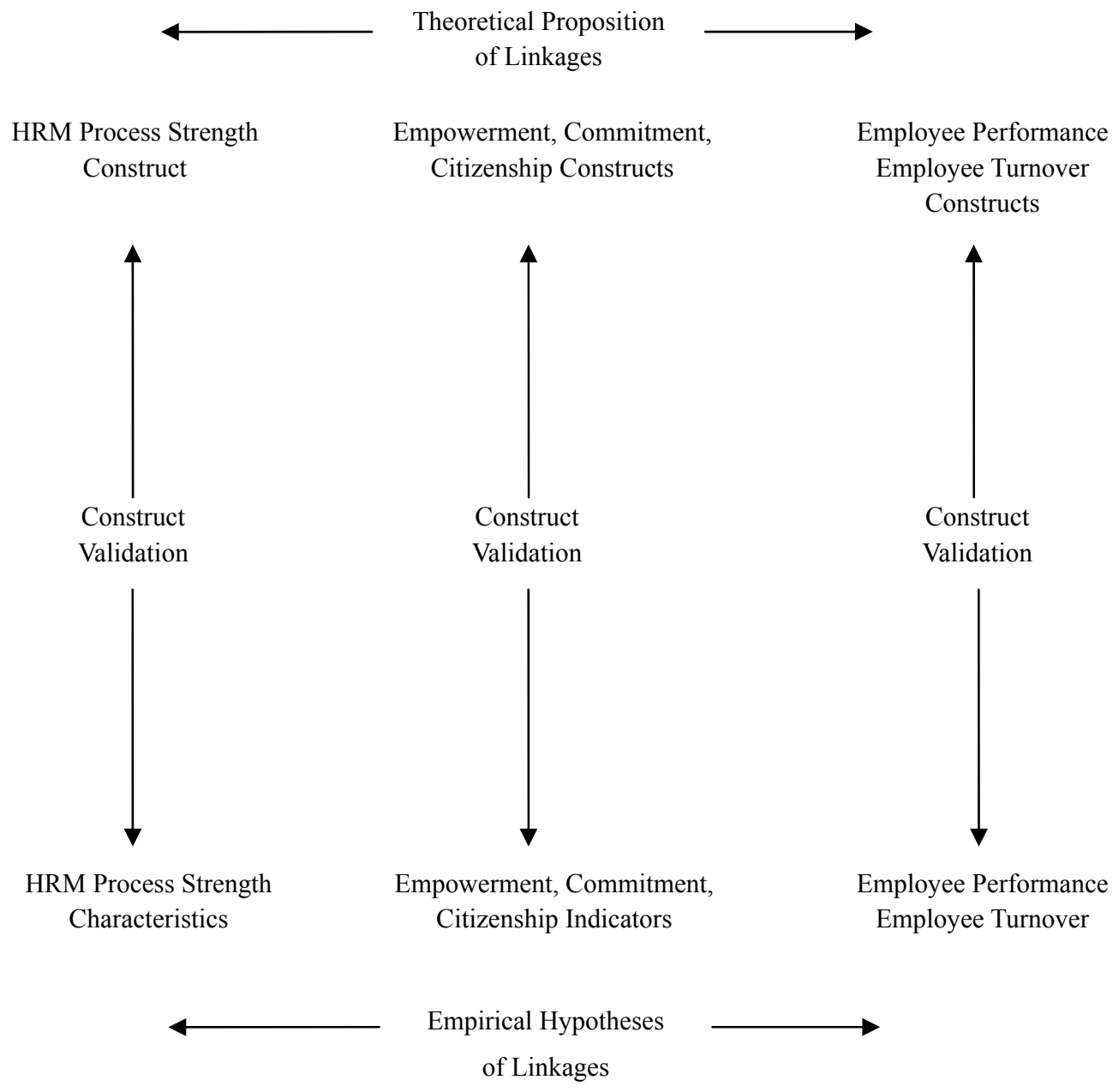

Figure 1. HRM - Firm Performance Linkages

\subsection{Data Collection}

The empirical study is based on data collected from both top-level managers and other senior, middle, and junior level managers of business organizations located across India. The data was collected during the period 
February-June 2007. Initially, the attempt was to choose sample organizations from among those who participate in the Business Today-Mercer-TNS Survey of India's Best Employers, based on the assumption that these organizations have a reasonable record of accomplishment of HRM system implementation, and are, at the same time distinguishable on the basis of their rankings. Business Today's issue dated November 5, 2006 included the names of organizations ranked one to ten as Best Employers through the years 2001 to 2006.

With the help of personal contacts, several of these 60 organizations were approached to participate in the survey by telephone and e-mail. Of those contacted, many declined, citing difficulties. Business Today was also approached to share the names of organizations ranked at the bottom in their Survey, but the publishers refused on the grounds of confidentiality. Given these setbacks, the author chose organizations based on convenience, provided they had a reasonable level of HRM system implementation, and were staffed with at least 50 managers. The organizations which agreed to participate represented a variety of industries: Agri Business, Banking, Consumer Durables, Energy, Foods and Beverages, Health Care, IT and ITES, Petroleum, and Publishing.

The author visited each of these companies and made a presentation to senior HR managers and others concerned, explaining the purpose and methodology of the study. Questionnaires were left with a senior HR manager of each participating company for distribution and retrieval.

There were two questionnaires: A1 - meant for top-level managers, and A2 - meant for the other managers in the organization. In all, $160 \mathrm{~A} 1$ and $1500 \mathrm{~A} 2$ questionnaires were distributed. $47 \mathrm{~A} 1$ and 796 A2 questionnaires from 12 organizations were returned. Of the $796 \mathrm{~A} 2$ respondents, 89 respondents were found to have responded to less than $95 \%$ of the items in the questionnaire, and were removed from the consideration set. Hence, the number of respondents considered for analysis of the A2 questionnaire was 707, of which Performance Appraisal Ratings were obtained for 236 respondents.

\subsection{Measures}

The A2 questionnaire (for all managers other than those at the top level) comprised of 108 items measured on a seven point scale ( 1 - Do not agree at all/To a small extent; 7 - Strongly agree/To a large extent). The items measured the following variables:

HRM system content:

Although HRM system content was not the focus of research in this study, 13 items (Ehrnrooth, 2002) on content were included in the survey instrument to serve as a reference of HRM practices for the respondents to assess HRM process strength characteristics (e.g., Many dimensions of your work situation are discussed during your performance appraisal - goal setting, career prospects, etc.; You receive a large amount of information through internal company information sharing.)

HRM system process strength:

1. Distinctiveness (13 items): (e.g., Are HR policies and systems formalized in writing? Is the content of HRM policies and systems easy for you to comprehend?)

2. Consistency (8 items): (e.g., Do you find consistency between what your organization's HRM policies and systems claim they do and what they actually do? Do you find the HRM policies and systems remaining stable over time?)

3. Consensus (22 items): 2 items to measure agreement among principal decision makers (e.g., Do senior line and HRM managers actively involve and work with each other in formulating and implementing HRM policies and systems?). The 20 items for measuring fairness were taken from Colquitt (2001).

All the other items measuring HRM process strength were developed specifically for this study.

Employee attitudes and behavior:

1. Psychological empowerment (8 items) validated by Spreitzer (1995)

2. Value commitment and continuance commitment (7 items) validated by Fenton-O'Creevy et al. (1997).

3. Organizational citizenship behavior (13 items) validated by Dyne et al. (1994).

The remaining 24 items were included for measuring control variables e.g., demographics, organizational support, leader support, etc. However, the relationships of these control variables with employee attitudes and behavior and employee performance and turnover are not being discussed in this paper. The A2 questionnaire also sought information on the respondent manager's appraisal rating for the previous three years from the HR department of his/her organization. 
The A1 questionnaire for top management members contained the following items: 1 item on employee performance taken from Moorman and Blakely (1995), 2 items on employee turnover developed for this study as well as items measuring number of managers and total employees in the organization.

\subsection{Data Analysis}

\subsubsection{Alpha Reliability}

Alpha values were computed for the manifest indicators in the case of HRM process strength (values ranged from 0.76 to 0.97 ), and latent constructs in the case of employee attitudes and behavior (the value for three of the four constructs ranged between 0.90 and 0.92 ; only continuance commitment indicated a value of 0.61 , below the threshold limit of 0.70 , posing a limitation). Alpha values were not required to be measured for the two dependent variables - employee performance and voluntary employee turnover. For employee performance, employee appraisal ratings and perceptions of the concerned top management of the employees were used as measures. For voluntary employee turnover, data provided by the organization was used as the measure.

\subsubsection{Univariate Statistics and Correlations}

Tables 1 and 2 below provide details of univariate statistics and zero-order correlations at the manifest indicator level for HRM process strength and at the latent construct level for HRM process strength and employee attitudes and behavior variables.

Table 1. Univariate Statistics and Correlations among Manifest Indicators of HRM Process Strength Variables

\begin{tabular}{|c|c|c|c|c|c|c|c|c|c|c|c|}
\hline & Mean & SD & 1 & 2 & 3 & 4 & 5 & 6 & 7 & 8 & 9 \\
\hline $\begin{array}{c}1 \\
\text { Visibility }\end{array}$ & 4.59 & 1.93 & 1.00 & & & & & & & & \\
\hline $\begin{array}{c}2 \\
\text { Understandability }\end{array}$ & 4.45 & 1.75 & 0.70 & 1.00 & & & & & & & \\
\hline $\begin{array}{c}3 \\
\text { Legitimacy of Authority }\end{array}$ & 4.52 & 1.96 & 0.78 & 0.67 & 1.00 & & & & & & \\
\hline $\begin{array}{c}4 \\
\text { Relevance }\end{array}$ & 4.35 & 2.13 & 0.72 & 0.69 & 0.81 & 1.00 & & & & & \\
\hline $\begin{array}{c}5 \\
\text { Instrumentality }\end{array}$ & 4.23 & 1.93 & 0.45 & 0.42 & 0.50 & 0.50 & 1.00 & & & & \\
\hline $\begin{array}{c}6 \\
\text { Validity }\end{array}$ & 4.45 & 1.81 & 0.64 & 0.57 & 0.68 & 0.72 & 0.55 & 1.00 & & & \\
\hline $\begin{array}{c}7 \\
\text { Consistent HRM Messages } \\
8\end{array}$ & 4.41 & 1.91 & 0.67 & 0.60 & 0.73 & 0.75 & 0.51 & 0.76 & 1.00 & & \\
\hline $\begin{array}{c}\text { Agreement Among Principal } \\
\text { HRM Decision Makers }\end{array}$ & 4.41 & 2.14 & 0.61 & 0.55 & 0.65 & 0.69 & 0.48 & 0.67 & 0.71 & 1.00 & \\
\hline $\begin{array}{c}9 \\
\text { Fairness }\end{array}$ & 4.24 & 2.27 & 0.68 & 0.58 & 0.70 & 0.71 & 0.47 & 0.71 & 0.72 & 0.68 & 1.00 \\
\hline
\end{tabular}

$\mathrm{p}<2.2 \mathrm{e}-16$

The results of the analysis show a high level of correlation (values range from 0.51 to 0.78 ) between the following manifest indicators of HRM process strength: visibility; understandability; legitimacy of authority; relevance; instrumentality; validity; consistent HRM messages; agreement among principal decision makers; and fairness. At the latent construct level for these indicators (distinctiveness, consistency, and consensus), the results show a similarly high level of correlations with values ranging between 0.75 and 0.80 . These results substantiate the proposed model assumption of the constructs being interrelated, though distinct.

The constructs of psychological empowerment, value commitment, continuance commitment, and organizational citizenship behavior are correlated to a lesser degree with the HRM process strength characteristics of distinctiveness, consistency, and consensus. These values range from 0.26 to 0.49 -further confirming the proposed model assumption that the constructs of HRM process strength are far removed from those denoting employee attitudes and behaviors. 
Table 2. Univariate Statistics and Correlations among HRM Process Strength and Employee Attitudes and Behavior Variables

\begin{tabular}{|c|c|c|c|c|c|c|c|c|c|}
\hline & Mean & SD & 1 & 2 & 3 & 4 & 5 & 6 & 7 \\
\hline $\begin{array}{c}1 \\
\text { Distinctiveness }\end{array}$ & 4.48 & 1.94 & 1.00 & & & & & & \\
\hline $\begin{array}{c}2 \\
\text { Consistency }\end{array}$ & 4.36 & 1.88 & 0.80 & 1.00 & & & & & \\
\hline $\begin{array}{c}3 \\
\text { Consensus }\end{array}$ & 4.33 & 2.21 & 0.77 & 0.75 & 1.00 & & & & \\
\hline $\begin{array}{c}4 \\
\text { Psychological Empowerment }\end{array}$ & 5.73 & 1.46 & 0.39 & 0.38 & 0.49 & 1.00 & & & \\
\hline $\begin{array}{c}5 \\
\text { Value Commitment }\end{array}$ & 6.13 & 1.32 & 0.30 & 0.26 & 0.35 & 0.73 & 1.00 & & \\
\hline $\begin{array}{c}6 \\
\text { Continuous Commitment } \\
7\end{array}$ & 4.66 & 3.10 & 0.35 & 0.30 & 0.34 & 0.34 & 0.33 & 1.00 & \\
\hline $\begin{array}{c}\text { Organizational Citizenship } \\
\text { Behavior }\end{array}$ & 5.78 & 1.26 & 0.30 & 0.26 & 0.36 & 0.68 & 0.68 & 0.37 & 1.00 \\
\hline
\end{tabular}

$\mathrm{p}<2.2$ e- 16

\subsubsection{Factor Analysis}

The study involved three factor analyses. The first, using principal component analysis, was designed to determine the distinct existence of items forming intended scales for HRM process strength and employee attitudes and behavior variables. Constrained to two factors, it was found that the causal variables, denoting HRM process strength characteristics, indeed, loaded on to a factor distinct from that of the variables of psychological empowerment, value commitment, continuance commitment, and organizational citizenship behavior.

The second factor analysis was performed to assess the discriminant validity of the HRM process strength items. The analysis was constrained to explain, at the least, a cumulative variance of 0.7 , with factor loading values of 0.4 or above being considered. This analysis brought forth a six-factor model, as opposed to the proposed nine-manifest indicator (or three-factor first order latent construct) model. Items measuring the manifest indicators of visibility, understandability, legitimacy of authority and relevance (first order latent construct "distinctiveness") loaded on to a single factor. Items meant to measure the first order latent construct "consistency" exhibited divergence from the proposed model. Two of the three items meant for the manifest indicator "instrumentality" loaded separately; and items measuring the manifest indicator "agreement among principal HRM decision makers" (proposed to be loaded with the manifest indicator "fairness" to denote the first order latent construct "consensus") loaded with the other items for "consistency" on to a single factor.

Respondents saw items measuring extent of linkage between work behaviors and personal outcomes as being distinct from the item measuring extent of authority that managers who implement HRM policies and systems have to link work behaviors to personal outcomes - i.e., perception of linkage is different from perception of authority. This could be one explanation for the divergence. Another could be that although items meant to measure agreement among line managers and HR managers on HRM policies and systems were proposed to denote consensus, respondents viewed the "agreement" indicator as contributing to consistency rather than consensus. Therefore, empirical evidence in this study indicates consistency to comprise of authority to link work behaviors to personal outcomes; validity; consistent HRM messages; and agreement among line managers and HR managers on HRM.

The other three factors were contributed by the items measuring "fairness". Fairness was envisaged as a single construct in the proposed model, denoting a unique dimension of consensus. However, surveyed respondents viewed fairness as a three-dimensional construct, with the three factors being procedural fairness, distributive fairness, and interactional and informational fairness. Historically, the construct of fairness or justice was considered as a two-factor model - procedural and distributive. This was expanded with the introduction of interactional justice, defined as the interpersonal treatment people receive, as procedures are enacted (Bies and Moag, 1986). Extant literature reveals that, at times, interactional justice is treated as a third type of justice and, at others, as a subset of procedural justice. Later, a four-factor structure for fairness was suggested (Greenberg, 1993). Colquitt (2001) 
empirically tested all four models and the results of his study indicated that the four-factor model provided the best fit followed by the three- and two-factor models respectively, while the one-factor model was the worst fitting. The results of the present study also seem to resonate with Colquitt's study in that fairness can best be conceptualized as a multi-factor model rather than a one-factor model.

The third factor analysis, meant to assess the discriminant validity of the constructs denoting psychological empowerment, value commitment, continuance commitment, and organizational citizenship behavior, brought forward a six-factor model in contrast to the proposed four-factor model. Here again, the objective was to explain a cumulative variance of at least 0.7 with factor loading values of 0.4 or above. Value commitment and continuance commitment were seen by respondents to be distinct constructs as proposed. However, psychological empowerment and organizational citizenship behavior, posited as single dimensional constructs, were viewed by respondents as two-dimensional constructs. Spreitzer's (1995) partially validated four-factor model scales (meaning; competence; self-determination; and impact) were used in this study to measure psychological empowerment. However, the items loaded on to two factors, namely role-related (meaning and competence) and behavior-related (self-determination and impact). Likewise, organizational citizenship behavior was measured using the four-factor model scales (individual initiative; interpersonal helping; loyal boosterism; and functional participation) of Dyne et al. (1994). But, the respondents viewed citizenship behavior to be a two-factor construct, namely that of conscientiousness (individual initiative and interpersonal helping) and extra role behavior (loyal boosterism and functional participation).

It was hypothesized that there are three first order latent constructs of HRM system process strength. The results of the factor analyses discussed above help to establish HRM system process strength as a second-order multi-dimensional construct comprising, not three first order constructs, but six distinct characteristics: (i) distinctiveness; (ii) instrumentality; (iii) consistency; (iv) procedural fairness; (v) distributive fairness; and (vi) interactional and informational fairness. Some of these characteristics are first order latent constructs (distinctiveness and consistency) and the others are manifest indicators (instrumentality, procedural fairness, distributive fairness, and interactional and informational fairness).

\subsubsection{Confirmatory Factor Analysis}

In this study, the measurement of the second order latent construct "HRM Process Strength", has largely been a developmental effort. Extensive item generation and refinement procedures were adopted to develop the observed measures (i.e., items) for the manifest and first order latent indicators. The procedures included: (i) examining existing, related items (e.g., fairness); (ii) generating items using the three first order latent constructs' theoretical definitions as a basis (e.g., distinctiveness); (iii) analyzing internal item consistency (alpha reliability analysis); and (iv) factor analyzing in a rigorous, quasi-confirmatory, hypothesis-testing mode. The final procedure that has been considered here, in order to establish convergent validity, is that of a Confirmatory Factor Analysis using a Structural Equation Modeling (SEM) approach.

It should be noted that scales validated in prior studies were used for the latent constructs of psychological empowerment, value commitment, continuance commitment, and organizational citizenship behavior. Hence, for the constructs representing dependent variables, procedures for establishing convergent validity were not considered necessary.

In order to examine the convergent validity of the second order latent construct "HRM Process Strength", the results of the factor analysis with regard to HRM process strength characteristics were assumed to be valid to specify the association of each latent construct with a specific number of observed variables.

The fit indices obtained are as:

(a) Baseline Comparisons

\begin{tabular}{llll}
\hline Model & $\begin{array}{l}\text { NFI } \\
\text { Delta1 }\end{array}$ & $\begin{array}{l}\text { TLI } \\
\text { rho2 }\end{array}$ & CFI \\
\hline Default Model & 0.896 & 0.895 & 0.896 \\
\hline
\end{tabular}

(b) Parsimony Adjusted Measures

\begin{tabular}{lcll}
\hline Model & PRATIO & $\begin{array}{l}\text { PNFI } \\
\text { rho1 }\end{array}$ & $\begin{array}{l}\text { PCFI } \\
\text { Delta2 }\end{array}$ \\
\hline Default Model & 0.903 & 0.862 & 0.894 \\
\hline
\end{tabular}


(c) RMSEA

\begin{tabular}{lllll}
\hline & RMSEA & LO 90 & HI 90 & P CLOSE \\
\hline Model & 0.06 & 0.0597 & 0.063 & 0.00 \\
\hline
\end{tabular}

It is often of interest to compare the relative fits of alternative, theoretically plausible models. However, a limitation of this study was that such a comparison was not attempted.

The finding here differs from that demonstrated by Li et al. (2011) and Coelho et al. (2012) in that, it is not only distinctiveness that is salient about HRM process strength, but that consistency and consensus also make contributions to the overall construct of HRM process strength. Figure 2depicts the convergent validity of the HRM process characteristics in the sample.

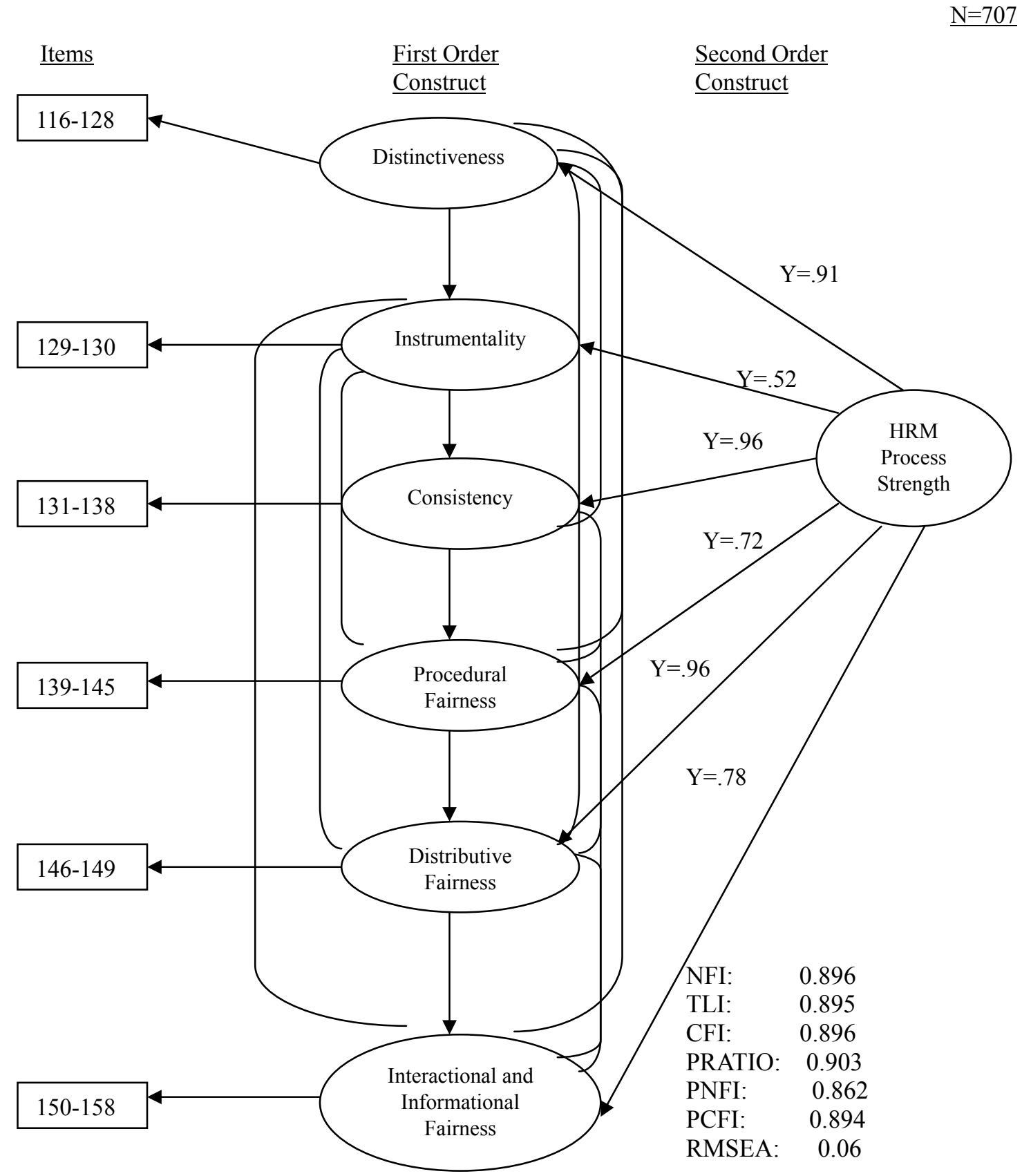

Figure 2. HRM Process Strength 
To summarize: HRM process strength characteristics are multi-dimensional and contribute to an overall construct of HRM process strength. In this study, factor analysis helped establish divergent validity, and structural equation modeling (SEM) analysis demonstrated convergent validity of the construct "HRM Process Strength". Hence, Hypothesis 1 is confirmed. That is, HRM process strength is a multi-dimensional construct and its various characteristics contribute to the totality of the construct.

\subsubsection{Linear Regression Analysis}

To test the associations between HRM process characteristics and employee attitudes and behaviors (Hypotheses 2 , $3 \mathrm{a}, 3 \mathrm{~b}$ and 4 ), linear regression analyses were carried out. In this study, the results of the regression analyses established several associations. Table 3 provides the results.

Table 3. Associations between HRM Process Characteristics and Employee Attitudes and Behaviors

\begin{tabular}{|c|c|c|c|c|c|c|}
\hline & $\begin{array}{l}\text { Psychological } \\
\text { Empowerment } \\
\text { (Role-Meaning } \\
\quad+ \\
\text { Competence) }\end{array}$ & $\begin{array}{l}\text { Psychological } \\
\text { Empowerment } \\
\text { (Behavior-Self } \\
\text { Determination } \\
\quad+\text { Impact) }\end{array}$ & $\begin{array}{c}\text { Value } \\
\text { Commitment }\end{array}$ & $\begin{array}{l}\text { Continuance } \\
\text { Commitment }\end{array}$ & $\begin{array}{c}\text { Organizational Citizenship } \\
\text { Behavior } \\
\text { (Conscientiousness-Individual } \\
\text { Initiatives + Personal } \\
\text { Helping) }\end{array}$ & $\begin{array}{c}\text { Organizational } \\
\text { Citizenship } \\
\text { Behavior } \\
\text { (Extra Role } \\
\text { Behavior- } \\
\text { Loyal } \\
\text { Boosterism + } \\
\text { Functional } \\
\text { Participation } \\
\end{array}$ \\
\hline Distinctiveness & & & & $\sqrt{ }$ & $\sqrt{ }$ & \\
\hline Instrumentality & & & & & $\sqrt{ }$ & \\
\hline Consistency & $\sqrt{ }$ & $\sqrt{ }$ & $\sqrt{ }$ & $\sqrt{ }$ & & $\sqrt{ }$ \\
\hline $\begin{array}{l}\text { Procedural } \\
\text { Fairness }\end{array}$ & $\sqrt{ }$ & & $\sqrt{ }$ & & $\sqrt{ }$ & $\sqrt{ }$ \\
\hline $\begin{array}{l}\text { Distributive } \\
\text { Fairness }\end{array}$ & $\sqrt{ }$ & $\sqrt{ }$ & $\sqrt{ }$ & & $\sqrt{ }$ & $\sqrt{ }$ \\
\hline $\begin{array}{l}\text { Interactional/ } \\
\text { Informational } \\
\text { Fairness }\end{array}$ & $\sqrt{ }$ & $\sqrt{ }$ & $\sqrt{ }$ & $\sqrt{ }$ & $\sqrt{ }$ & $\sqrt{ }$ \\
\hline $\begin{array}{l}\text { Multiple R } \\
\text { Squared }\end{array}$ & 0.23 & 0.35 & 0.23 & 0.18 & 0.23 & 0.16 \\
\hline $\begin{array}{l}\text { Adjusted R } \\
\text { Squared }\end{array}$ & 0.23 & 0.34 & 0.23 & 0.18 & 0.22 & 0.16 \\
\hline $\mathrm{p}$-value & 0.00 & 0.00 & 0.00 & 0.00 & 0.00 & 0.00 \\
\hline
\end{tabular}

HRM process characteristics of interactional and informational fairness, procedural fairness, distributive fairness and consistency have been found to have very important roles to play in engendering attitudes and behaviors of psychological empowerment, value commitment, continuance commitment and organizational citizenship behavior. In this study, the process characteristics of distinctiveness were found to be more important, in relation to continuance commitment and citizenship behavior (conscientiousness-individual initiative and interpersonal helping); and instrumentality only in relation to citizenship behavior (conscientiousness).

The objective of this study is limited to the extent of establishing the primacy of HRM process strength characteristics in influencing employee attitudes and behaviors, employee performance and employee turnover. The results of the linear regression analysis provide reasonable confirmation that the stated objective is realized in terms of employee attitudes and behaviors.

Hypotheses 2 (HRM process strength characteristics - Psychological Empowerment); 3a (HRM process strength characteristics - Value Commitment); $3 \mathrm{~b}$ (HRM process strength characteristics - Continuance Commitment); and 4 (HRM process strength characteristics - Organizational Citizenship Behavior) are confirmed. 


\subsubsection{Variance Analysis}

\subsubsection{Within-Group Consistency Analysis}

James, Demaree and Wolf (1983) proposed the "rwg" procedure for assessing agreement among respondents in a group provided the scales are uniform across constructs and the constructs exhibit significant alpha values and validity. rwg values at or above 0.70 are generally considered to indicate high inter-rater reliability.

In this study, the preconditions for rwg tests usage were adequately met. rwg was computed for each of the three constructs that constitute HRM process strength characteristics and for each of the intermediate variable constructs. This computation was not done for the dependent variables. The rwg values for each of the constructs for all the 12 organizations were found to be 0.70 or above. These values indicate high within-group consistency of responses. These values, when combined with inter-item reliability (Cronbach's alpha), construct validity, and the between-organization differences described in Section 4.3.6.2, provide justification for aggregating individual-level responses to measure organization-level constructs.

\subsubsection{Between-Organizations Consistency Analysis}

Between-organization differences were calculated using ANOVA, since the three assumptions of normality (the values in each group are normally distributed); homogeneity (the variance within each group should be equal for all groups); and independence of error (the variation of each value around its own group mean should be independent for each value) were held to be valid in this case. Since 12 groups were involved, the F test was used to test for significance. And the values obtained (Table 4) provide evidence of between-organization differences. The analysis shows that a significant proportion of the total variation in responses to each construct is explained by organizational membership.

The factor validity of the responses, the within-organization consistency of responses, and the between-organization differences justify composing measures of HRM process strength characteristics and employee attitudes and behavior for each organization. Further, within-organization agreement and between-organization differences establish that an appropriate work-unit level has been selected for study.

Table 4. Between Group Analysis for 12 Organizations

\begin{tabular}{lcc}
\hline \multicolumn{1}{c}{ Construct } & F Value & P \\
\hline Distinctiveness & 6.66 & $1.181 \mathrm{e}-10$ \\
Instrumentality & 5.89 & $3.450 \mathrm{e}-09$ \\
Consistency & 6.42 & $3.423 \mathrm{e}-10$ \\
Procedural Fairness & 6.81 & $6.198 \mathrm{e}-11$ \\
Distributive Fairness & 6.03 & $1.893 \mathrm{e}-09$ \\
Interactional and Informational Fairness & 6.76 & $7.609 \mathrm{e}-11$ \\
Psychological Empowerment -Role & 6.74 & $8.266 \mathrm{e}-11$ \\
Psychological Empowerment - Behavior & 10.85 & $<2.2 \mathrm{e}-16$ \\
Value Commitment & 9.41 & $6.699 \mathrm{e}-16$ \\
Continuance Commitment & 4.74 & $4.857 \mathrm{e}-07$ \\
Organizational Citizenship Behavior - Conscientiousness & 5.61 & $1.157 \mathrm{e}-08$ \\
Organizational Citizenship Behavior - Extra Role Behavior & 7.03 & $2.291 \mathrm{e}-11$ \\
\hline
\end{tabular}

\subsubsection{Hierarchical Linear Modeling Analysis and Regression Analysis}

Hofmann and Gavin (1998) identify four dominant paradigms from which researchers have investigated relationships between variables that span multiple levels of analysis, viz. incremental, mediational, moderational and separate. James et al. (1990) are of the view that the theoretical and conceptual considerations involved in the study of climates best fit the mediational paradigm. The theory pertaining to climate proposes that objective contextual factors influence individual outcome variables through the meanings that individuals attach to these factors. According to Hofmann and Gavin (1998), either grand mean centering or group mean centering with the mean 
values reintroduced into the level-2 intercept model provides an appropriate test of this model. In this study, an employee level model was constructed for HRM process characteristics for each of the surveyed companies.

Briefly, the procedure adopted is described below:

i) For each construct (say, distinctiveness), a "score" for a respondent belonging to a company was computed by combining the item responses of the respondent and the factor coefficients obtained in the factor analysis Section 4.3.3.

The employee level model postulates that ideally each of these scores is actually a sum of three numbers: a score for the company; a score for each construct and random error. Thus, the equation: Item response for an employee (score) $=$ Effect of Construct (say, Distinctiveness) + Effect of company + Random Error. However, due to individual differences among the respondents belonging to a particular company, some departure from the postulated model is likely.

ii) A model was fitted to a company's respondent data to find the mean of the company score and the constructs' score such that the departures are as small as possible.

iii) To ensure that the constructs' scores are significant, a variance analysis was performed (ANOVA).

Table 5 provides company-wise details for HRM process strength characteristics. The p-values obtained (2.2e-16) show that the constructs are indeed important at the company level. The company-wise scores were saved for use in hierarchical linear model analysis to examine relationships between HRM process strength variables and the variables of employees' performance and employees' turnover at the company level.

Table 5. HRM Process Characteristics

\begin{tabular}{|c|c|}
\hline Company & Construct Score* \\
\hline $\mathrm{C} 1$ & 34.34 \\
\hline $\mathrm{C} 2$ & 33.87 \\
\hline $\mathrm{C} 3$ & 35.89 \\
\hline $\mathrm{C} 4$ & 35.60 \\
\hline $\mathrm{C} 5$ & 35.98 \\
\hline C6 & 32.43 \\
\hline $\mathrm{C} 7$ & 32.58 \\
\hline $\mathrm{C} 8$ & 40.89 \\
\hline $\mathrm{C} 9$ & 38.47 \\
\hline $\mathrm{C} 10$ & 37.07 \\
\hline $\mathrm{C} 11$ & 33.16 \\
\hline $\mathrm{C} 12$ & 33.26 \\
\hline
\end{tabular}

The company level data on employee performance and employee turnover (A1 questionnaire) was uniquely preserved, company-wise (multiple responses for an item from the same company were averaged). These values were then regressed on the company scores for HRM process strength.

To test the hypothesized relationships between organizational performance dimensions of employee performance and voluntary employee turnover on the one hand, and HRM process strength characteristics on the other, both regression analysis and hierarchical linear modeling analyses were deployed. Employee performance data was collected at the individual level (for 235 respondents). Regression analysis was used to test the relationships between employee performance and HRM process strength characteristics. Hierarchical linear modeling analysis was used where independent variables were measured at the individual level and the dependent variables at the company level (employee performance and employee turnover).

When employee performance appraisal data was regressed on HRM process characteristics, it was found that four HRM process strength characteristics - consistency, instrumentality, procedural fairness and distributive fairness showed strong predictive power on employee performance appraisal rating. The characteristics of distinctiveness and 
interactional and informational fairness did not show predictive power. (Multiple R Squared $=0.15$; Adjusted $\mathrm{R}$ Squared $=0.13 ; \mathrm{p}$-value $=1.128 \mathrm{e}-16$ ).

This affirms Hypothesis 5a, in that HRM system characteristics relate positively to employee performance, which includes quality and efficiency.

Since the above regression analysis was done with only 235 respondents, the association between employee performance and HRM process characteristics was also tested using hierarchical linear modeling analysis. The HLM analysis did not establish any significant association between employee performance and HRM process characteristics. This is largely due to the fact that top managements' perceptions of their employees' performance did not differ significantly between companies, although this study did show significant between-company variance concerning HRM process strength characteristics. This is a limitation.

To sum up, HRM process strength characteristics relate positively to the quality and efficiency of employees' work performance based not on top managements' perceptions of their employees' performance, but based on employees' performance appraisal ratings. When examining relationships between employee performance and HRM in the future, it is recommended that actual performance ratings of individual employees be used rather than perception based performance ratings of employees.

To test the relationships between voluntary employee turnover and HRM process characteristics, hierarchical linear modeling analysis was deployed. The results showed that HRM process characteristics are inversely associated with voluntary employee turnover in the senior management category, the regression coefficient being -0.25 , (Multiple $\mathrm{R}$ Squared $=0.27$; Adjusted R Squared $=0.19 ; \mathrm{p}$-value $=0.09$.), thus partially confirming Hypothesis $5 \mathrm{~b}$, and indicating that senior management turnover is influenced by HRM process strength characteristics. The question remains as to why turnover of junior and middle management categories is not explained. Many companies are struggling with high staff turnover in spite of the efforts that they are making to improve HRM system content and HRM implementation processes. These efforts do not seem to match the three aspirations that employees are able to meet by switching companies frequently: higher salary, better-sounding title, and greater responsibility.

\section{Discussion}

A fundamental contribution of this study is in demonstrating that HRM system process strength is a critical component in explaining and predicting employee attitudes and behaviors, employee performance, and voluntary employee turnover. The empirical findings demonstrated in this research contribute to knowledge about HRM process strength in several areas.

First, the core concepts of HRM process, situational or climate strength, empowerment, commitment, and citizenship behavior derived from extant literature guided the operational definitions and the models for composing higher-level (i.e., organization) measures of each construct from individual-level responses. The dependent variables of employee performance and employee turnover were also derived from organizational literature.

Second, empirical evidence that HRM process characteristics and employee attitudes and behaviors are distinct constructs was provided by factor analysis of scales developed by the author and from validated instruments, and used as indicators of the latent constructs. Factor analysis of scales used as indicators of the latent constructs and manifest indicators comprising HRM process characteristics showed adequate divergent validity, demonstrating their uniqueness despite being interrelated. Further, structural equation modeling provided confirmation that HRM process strength characteristics possess convergent validity.

Third, within-organization agreement of responses and between-organization differences in responses indicated that the constructs of HRM process, empowerment, commitment, and citizenship could be meaningfully composed by organizations to measure their organizational HRM process strength or HRM climate, and employee attitudes and behaviors.

Fourth, linear regression and hierarchical linear model analyses provided estimates of linear and cross-level relationships that link HRM process strength to employee attitudes and behaviors, and these two sets of variables to employee performance and turnover. Stronger HRM climates were associated with more positive work attitudes, higher employee performance, and lower employee turnover.

The findings support the view that the way HRM is implemented (as perceived by individuals) enhances overall HRM effectiveness. HRM process characteristics of interactional and informational fairness, procedural fairness, distributive fairness, and consistency have very important roles to play in engendering attitudes and behaviors of 
psychological empowerment, value commitment, continuance commitment, and organizational citizenship behavior. Further, consistency, instrumentality, procedural fairness, and distributive fairness should have strong predictive power on employee performance (Appraisal Rating). Furthermore, HRM process strength was inversely related to employee turnover in the senior management category.

However, the hierarchical linear model analysis linking HRM process strength to employee performance at the organizational level and employee turnover in junior and middle management categories did not show any significant association.

This study set out to explicate the theory concerning HRM implementation process characteristics. The proposed theorization was that employee perceptions of organizational level HRM process characteristics would reflect the strength of HRM. This strength would influence the formation of an organizational HRM climate for empowerment, commitment, and citizenship behavior. HRM process strength was hypothesized to influence organizational performance in terms of employee performance and voluntary employee turnover.

Extant research makes available empirical findings which demonstrate the validity of the theorizations of psychological empowerment, commitment, and citizenship behavior and their links to employee performance and voluntary employee turnover. The significant contribution of this research and similar others establish the significance of HRM process characteristics, contributing to knowledge building in this area. All the studies have used cross-sectional data and relied on single informants to gather data. These are limitations but they also suggest some valuable directions for future research. The HRM process strength construct requires more validation at multiple levels and among multiple actors. In organizational situations, the system and process of HRM interact to elicit desired employee attitudes and behaviors that, in turn, impact organizational performance. It would be beneficial if further studies tested such interactions and interrelationships more rigorously. Future research would also benefit by pursuing multi-sourcing longitudinal studies.

\section{HRM Process Strength - The Implementation}

The empirical studies discussed in this paper have argued that Kelley's (1973) attribution theory and Mischel's (1973) explication of a "strong situation" help to identify features of the HRM system process that would assist in fostering the emergence of a strong organizational HRM climate, as opposed to idiosyncratic psychological HRM climate perceptions. Supporting theory and demonstrated empirical evidence converge to propose that when employees perceive the HRM system process as being high in Distinctiveness, Instrumentality, Consistency, and Fairness, it creates a strong HRM situation. This section will attempt to answer the question: "How does an organization embed these characteristics in the implementation of HRM systems?"

\subsection{Distinctiveness}

As mentioned in Section 3, distinctiveness generally refers to features that enable the HRM system to stand out in the environment, thereby capturing attention and arousing interest (Bowen \& Ostroff, 2004). The features usually associated with distinctiveness are visibility, understandability, legitimacy of authority, and relevance.

Organizations strive to achieve distinctiveness by formalizing HRM policies and systems as opposed to relying on an informal way of working. The contents of HRM policies and systems are made clear, visible, and transparent to employees, and the ubiquity of information technology has helped to achieve this to a great extent. In addition, HRM policies and systems seek to cover and to be applicable to a larger proportion of employees. For example, earlier appraisal and development planning systems were not applicable to supervisory staff, unionized employees, or even junior managers. However, today, these systems cover almost all categories of employees without exception. Though the properties of these HRM systems may vary across different categories, the property of applicability is universal.

In order to improve the person-organization alignment, companies are making great efforts to clarify individual role expectations and promote group cohesiveness. These efforts extend to fostering alignment between the qualitative goals of both the individual and the organization, e.g. in terms of speed, service, innovation, etc. The intention is that they should be carried out in such a way that individuals are willing to work towards goals that allow them to meet their needs, and, in doing so, also enable the organization to achieve its mission. Such an alignment of goals is also engendered by and between members of different hierarchical positions in the organization's structure as well as between an individual and the other individuals within a constituency.

One way to enhance the "relevance" of HRM in organizations is to promote goal congruence. Another is to ensure that HR managers possess capabilities to not only deliver HRM basics such as recruiting, compensation and benefits but to also deliver these services in a way that directly supports the implementation of the organization's strategy. 
This calls for HR staff to possess business-related capabilities. Further, in organizations where HRM is found to be business-relevant, the HR function is found to extend its focus from the services it provides to the decisions it supports. In such organizations, the mission of the HR function is to increase organizational success by providing inputs to improve decisions that depend on or impact people. These organizations consider it an imperative to not only systematically build, business-related capabilities and HRM skills in HR staff, but also to develop a logical, deep and coherent framework to link HRM to strategic business success - a framework that Boudreau and Ramstad (2007) refer to as HRM decision science.

The salience or relevance of HRM contributes to the HR function being seen as a credible, high-status entity thereby lending it legitimacy of authority. Experience shows that HRM implementation gains legitimacy when HR roles are clarified and determined in terms of who takes the responsibility for HRM implementation and transmission of the HRM message - line managers or HR professionals. Additionally, HRM legitimacy is strengthened when there is organizational consensus on the "functional" roles that HR professionals are expected to perform (Dorenbosch et al, 2006). HR roles are also a key component of the HRM process through which employee attitudes and behaviors are affected and, since more often than not, the implementation of these processes and policies involve line managers, it is imperative that they be HRM "literate" and possess the necessary skills.

When HRM policies and systems are implemented in a manner that is visible, understandable, relevant and legitimate, organizations will find it easier to retain talent.

\subsection{Instrumentality}

Instrumentality refers to the perceptions of employees regarding the likely consequences of their work-related behaviors. Organizations rely on their performance management processes to align or integrate organizational and individual objectives to achieve organizational effectiveness. This integration cannot be achieved by merely articulating the broad goals and objectives of the organization. Individuals and groups must also be able to communicate their expectations - what they should do, how they should manage, the support and resources they need/require, and how their talent should be used. Protocols are required to systematize and sustain such understanding and communication on performance. Experience shows that some of the most commonly used protocols are the Management by Objectives (MbO) method, the Balanced Scorecard (BSc) framework, and the Integrated Branding (IB) approach. These protocols work towards the objective of helping individuals gain an understanding of how to contribute - how their actions and behaviors can align with the objectives of the organization.

In organizations that rely on performance management processes to establish employee line-of-sight to objectives and behaviors organizational objectives and strategy are described in a more disciplined way, not just through company-wide information sessions, but also by involving employees through direct and personal communication. Such a discipline offers several benefits: the likelihood of successful strategy implementation is increased; people are encouraged to adopt behaviors that are necessary to ensure that short-term actions do not jeopardize, but, to the contrary, help secure the organization's long-term goals. The performance management processes clearly signal to each employee what the key drivers of success are and provide him or her with an opportunity to define how they contribute to that success. They also create a consistent language that guides action. By allowing every employee to participate in the organization's performance management processes, a spirit of involvement and partnership is nurtured. This, in turn, leads to better results for everyone involved. Organizations find that employee performance is consistent and employee retention is enhanced when linkages between individuals' actions and personal consequences such as rewards, etc. are reinforced. Such reinforcement is achieved by being consistent over time, people, and situations. Organizations benefit from a stronger performance management system with minimal variance in employee performance.

Instrumentality, therefore, serves as a key characteristic of HRM implementation processes.

\subsection{Consistency}

Consistency refers to establishing an effect over time and modalities whereby the effect occurs each time the entity is present, regardless of the form of the interactions. Consistency comprises of authority to link work behaviors to personal outcomes, consistency between HRM precept and practice, mutual reinforcement of HRM practices, temporal stability of HRM practices, and consensus on HRM among HRM decision makers.

Consistency defines the character of HRM implementation and stands for excellence in HRM execution. While most organizations are not found wanting in making promises to their employees, what sets an organization apart is the courage of conviction to strive to honor those promises, thereby engendering high levels of trust among employees - 
the most important attribute in an employment relationship. Consistent organizational actions support trusting relationships between the employees and the organization. When such relationships exist, employees are more willing to be vulnerable to organizational actions as they are based on the expectation that the organization will act in their interest, irrespective of their ability to monitor or retaliate against the organization.

Companies that are committed to HR excellence ensure that HRM practices send a consistent message to employees about what is expected and valued, and what is rewarded. As a result, their employees receive clear signals as to what their actions should be. Consistent HRM also means that HRM practices must connect to and reinforce each other to produce the outcomes the organization wants to achieve. The organization cannot be doing one thing in one practice that produces a counter result in another. High-performing HRM systems have practices that "talk" to each other. These practices communicate and deliver results for each other. Though it is difficult, companies find that achieving HRM consistency gives them a distinct edge in competing for, seeking and retaining scarce talent.

For employees, when they find that HR decisions are arrived at through a consensual process among decision makers, they usually find these messages to be consistent in both delivery and implementation. However, sometimes, employees receive contradictory messages from line managers who implement HRM and HR staff who design systems and guide implementation. They may also find that HRM practitioners (line managers and HR staff) are not authorized to link their behaviors and actions to their personal consequences. In order to maintain and strengthen consistency, HRM practitioners should send mutually reinforcing messages and be authorized to link employee actions to consequences. The implementation of a chosen HRM system and its practices should be "persisted" on and remain stable over time in organizations so that employees attribute consistency to HRM. Chasing "fads" and resorting to quick fixes is not only a waste of money, time, and effort, but, also puts HRM credibility at stake.

\subsection{Fairness}

The results of this study conclusively establish that fair treatment of employees promotes employee empowerment, value commitment, continuance commitment, and citizenship behaviors. In addition, procedural fairness and distributive fairness showed strong predictive power on employee performance. The study also found considerable evidence relating employees' perceptions of HRM fairness to employee retention levels in organizations.

Employees expect fairness in HR decision-making and judge the fairness of an organization based on HR decisions regarding staffing, performance appraisal, reward systems, etc. For example, employees judge the fairness of their performance appraisal ratings and the rewards tied to those ratings (distributive fairness), the consistency and appropriateness of the appraisal process (procedural fairness), and the respect, explanations, and feedback that accompany the communication of performance ratings (interactional and informational fairness).

Distributive fairness is a measure allocating the appropriateness of an outcome or reward as perceived by an individual, given his or her contributions. The distribution of rewards can be based on the following three principles: (a) Equity (individuals are rewarded based on their input levels) that focuses on comparisons with others; (b) Equality (all individuals receive equal rewards) that focuses on an equal share for all; and (c) Need (individuals who are most in need of rewards benefit first) (Folger \& Cropanzano, 1998).

To enable employees to perceive distributive fairness, companies formally structure the principles into outcome allocation decisions. For example, the equity rule of allocation is applied for conflicts or grievances concerning performance management and appraisal. The equality rule of distribution is practiced when allocating opportunities for attaining rewards, regardless of individual characteristics such as religion, caste, creed, gender, etc. The need rule of distribution is put to use in redressing grievances of people who are differently abled or individuals who are faced with certain unique, and often tragic, circumstances, say loss of family members, chronic ailments, etc.

Procedural fairness is related to three principles - engagement; explanation; and expectation clarity identified by Kim and Mauborgne (1997) as the three bedrock elements of fair process. Organizations promote procedural fairness by formalizing a structure comprising of two parts: (i) Choice and Decision Control and (ii) Voice and Process Control (Folger \& Cropanzano, 1998). Taking the example of remuneration and rewards, this structure is accomplished through employee representation (e.g. through unions) or participation on remuneration committees. A latter development is that individuals negotiate idiosyncratic deals (i-deals) with their employers (Rousseau, Ho, \& Greenberg, 2006). Formally defined, i-deals refer to voluntary, personalized arrangements of a non-standard nature negotiated between individual employees and their employers regarding terms that are mutually beneficial.

Interactional fairness concerns the interpersonal treatment people receive from decision makers, which may have little or nothing to do with formal procedures. Informational fairness calls for providing "explanations" and not excuses. The absence of any explanation at all for a decision, other than an arbitrary and capricious attitude, is 
considered egregiously unfair and a form of manipulation. Explanations, on the other hand, provide justifications for a decision. For example, to reduce initial uncertainty when administering employee selection, organizations provide candidates with information regarding the job and selection process in advance. After the selection process, they provide feedback on how the candidates performed. The selection process is conducted in a manner that reflects professionalism and respect in all interactions with the applicant.

Concerns about fairness first arise when a person accepts a job - this marks the beginning of an employment relationship. Organizations demonstrate fairness in the way they treat people on the job, the way decisions on appraisals, promotions and transfers are made, and the way conflicts are resolved. Though fair process is powerful and simple, yet we find that it is not commonplace. There are several reasons for this. In some instances fair process is confused with fair outcomes. As long as managers consider that employees have been provided with fair outcomes, they do not focus on the process. There are also managers who consider fair process a threat to their exercise of power. They prefer to keep information to themselves and not share it with others, leaving the rules of the game ambiguous and vague. Thirdly, managers are unconvinced by evidence showing that people are willing to accept outcomes that are not wholly in their favor as long as they perceive the process leading to those outcomes as fair. Ultimately, if managers are able to build trust through fair processes, HRM implementation will derive substantial gains.

\section{Recommendation}

The precept and practice of HRM process strength provides two key advantages. The first advantage is that it provides a logical, reliable, and consistent framework that enhances decisions about HRM implementation. The characteristics of Distinctiveness, Instrumentality, Consistency, and Fairness (Procedural, Distributive, and Interactional/Informational) together, denoting HRM process strength, provide a common framework to deal with issues pertaining to HRM implementation. The empirical study, having established substantive validity of the relationships between HRM process strength and the attitudes and actions of employees, has confirmed the theoretical approach. The approach argues that HRM processes serve as communication mechanisms signaling employees to engage in certain behaviors.

For employee retention and employee performance, it pays to implement HRM by embedding the characteristics of Distinctiveness, Instrumentality, Consistency and Fairness in organizational working.

This leads to the second advantage of HRM process strength. It provides a teachable framework that could support guiding others on how to implement HRM. Most often, HR practitioners learn how to implement HRM in their own way, with little systematic instruction or development. Since people management capability is critical for organizations today, this capability requires rapid scaling up to encompass HR staff and others outside HR. If HRM implementation is carried out by an organization in myriad individual ways, this would drastically impede scaling up in comparison to access to a common, teachable framework.

The journey towards stronger linkage between HRM and Firm performance can begin from many starting points, and often with the issues in which HRM is already engaged. This study along with others argues that reflecting on and understanding HRM processes is yet another proven and potent way to engage in the journey.

\section{Conclusion}

This study has attempted to answer several questions about HRM system process strength by exploring the underlying dynamics. It helps to understand why organizations experience variability in performance despite having similar HRM process content, and also in facilitates diagnosis. The study presents a clear model of HRM process strength that enables the assessment of HRM system implementation. HRM process strength can also assist in making external evaluations of an organization's HRM. However, although HRM process strength is convenient for comprehension, diagnosis and assessment, it is not without its problems.

HRM process strength is dependent on organizational culture, and cultures are difficult to measure, let alone change. HRM system process characteristics must be tempered by HRM system content characteristics and organizational performance focus. Not only must HR professionals possess HRM implementation skills, but line managers must also be HRM literate and adept in HRM implementation. Organizations must communicate clearly, fairly, and unambiguously their understanding of the links between HRM system implementation and its performance in a way that is balanced and objective, following a process that is susceptible to review. 
While skill in implementing HRM is a great strength for an organization, it can also be an inherent weakness. Processes tend to rigidize organizations, undermining flexibility and individuality. As a result, HRM system implementation could end up resembling any other system implementation - checklist-led, mechanistic, and precise.

The overwhelming body of theory on crafting strategy has left people floundering when it came to implementation. HRM is confronted with a similar predicament - theory on content surpasses the volume of literature on implementation. Given the complexity involved, it is extremely difficult to offer convincing empirical evidence of the effects of HRM systems. Even if claims are made that there is strong evidence of a relationship between HRM and organizational performance, there is only fragmentary evidence of how HRM might actually impact organizational performance. Hopefully, this study's present effort at theory building on HRM process strength could begin to help explain and predict how HRM systems can lead to desired organizational outcomes.

\section{References}

Bacharach, S.B. (1989). Organizational Theories: Some Criteria for Evaluation. Academy of Management Review, 14, 496-515.

Barnard, C.I. (1938). The Functions of the Executive. Cambridge, MA: Harvard University Press.

Becker, B., \& Gerhart, B. (1996). The Impact of Human Resource Management on Organizational Performance: Progress and Prospects. Academy of Management Journal, 39, 779-801.

Bies, R.J., \& Moag, J.F. (1986). Interactional Justice: Communication Criteria of Fairness. In R.J. Lewicki, B.H. Sheppard, \& H.H. Bazermann (Eds.), Research on Negotiations in Organizations, 1,(pp. 43-55). Greenwich, CT: JAI Press. (Cited in Colquitt, J.A. (2001). On the Dimensionality of Organizational Justice: A Construct Validation of a Measure. Journal of Applied Psychology, 86, 386-400).

Boudreau, J.W., \& Ramstad, P.M (2007). Beyond HR: The New Science of Human Capital. Boston, MA: Harvard Business School Press.

Bowen, D.E., Gilliland, S.W., \& Folger, R. (1999). HRM and Service Fairness: How Being Fair with Employees Spills Over to Customers. Organizational Dynamics, 27(3), 7-23.

Bowen, D. E., \& Ostroff, C. (2004). Understanding HRM-Firm Performance Linkages: The Role of the "Strength" of the HRM System. Academy of Management Review, 29, 203-221.

Coelho, J.P., Cunha, R.C., Gomes, J.F.S., \& Correia, A. (2012). Developing and Validating a Measure of the Strength of the HRM System: Operationalizing the Construct and Relationships among its Dimensions. Working Paper 0562. Nova School of Business \& Economics.

Colquitt, J.A. (2001). On the Dimensionality of Organizational Justice: A Construct Validation of a Measure. Journal of Applied Psychology, 86, 386-400.

Colquitt, J.A., Noe, R.A., \& Jackson, C.L. (2002). Justice in Teams: Antecedents and Consequences of Procedural Justice Climate. Personnel Psychology, 55, 83-109.

Delbecq, A., \& Mills, P.K. (1985). Managerial Practices that Enhance Innovation. Organizational Dynamics, 14(1), 24-34.

Delery, J.E., \& Doty, D.H. (1996). Modes of Theorizing in Strategic Human Resource Management: Tests of Universalistic, Contingency and Configural Performance Predictions. Academy of Management Journal, 39, 802-835.

Dorenbosch, L., de Reuver, R., \& Sanders, K. (2006). Getting the HR Message Across: The Linkage between Line-HR Consensus and "Commitment Strength" among Hospital Employees. Management Revue, 17, 274-291.

Drazin, R., Glynn, M.A., \& Kazanjian, R.K. (1999). Multilevel Theorizing About Creativity in Organizations: A Sensemaking Perspective. Academy of Management Review, 24, 286-307.

Dyne, L.V., Graham, J.W., \& Dienesch, R.M. (1994). Organizational Citizenship Behavior: Construct Redefinition, Measurement and Validation. Academy of Management Journal, 37, 765-802.

Ehrnrooth, M. (2002). Strategic Soft Human Resource Management - The Very Idea: An Exploration into a Social Science. Swedish School of Economics and Business Administration, Helsingfors. 
Fenton-O'Creevy, M.P., Winfrow, P., Lydka, H., \& Morris, T. (1997). Company Prospects and Employee Commitment: an Analysis of the Dimensionality of the BOCS and the Influence of External Events on Those Dimensions. British Journal of Industrial Relations, 35, 593-608.

Ferris, G.R., Hochwarter, W.A., Buckley, M.R., Harrell-Cook, G., \& Frink, D. D. (1999). Human Resource Management: Some New Directions. Journal of Management, 25, 385-415.

Fiske, S.T., \& Taylor, S.E. (1991). Social Cognition. New York: McGraw-Hill.

Folger, R., \& Cropanzano, R. (1998). Organizational Justice and Human Resource Management. Newbury Park, CA: Sage.

Frederiksen, N. (1972). Toward a Taxonomy of Situations. American Psychologist, 27, 114-123.

Gratton, L., \& Truss, C. (2003). The Three-Dimensional People Strategy: Putting Human Resources Policies into Action. Academy of Management Executive, 17(3), 74-86.

Greenberg, J. (1993). The Social Side of Fairness: Interpersonal and Informational Classes of Organizational Justice. In R. Cropanzano (Ed.), Justice in the Workplace: Approaching Fairness in Human Resource Management, (pp. 79-103). Hillsdale, NJ: Erlbaum.

Hofmann, D.A., \& Gavin, M.B. (1998). Centering Decisions in Hierarchical Linear Models: Implications for Research in Organizations. Journal of Management, 24, 623-641.

Huselid, M.A. (1995). The Impact of Human Resource Management Practices on Turnover, Productivity and Corporate Financial Performance. Academy of Management Journal, 38, 635-672.

Jackofsky, E.F., \& Slocum, J.W., Jr. (1988). A Longitudinal Study of Climates. Journal of Organizational Behavior, 9, 319-334.

James, L.R., Demaree, R.G., \& Wolf, G. (1993). rwg: An Assessment of Within-Group Interrater Agreement. Journal of Applied Psychology, 78, 306-309.

James, L.R., James, L.A., \& Ashe, D.K. (1990). The Meaning of Organizations: The Role of Cognition and Values. In B. Schneider (Ed.), Organizational Climate and Culture, (pp. 40-84). San Francisco: Jossey-Bass.

Kelley, H.H. (1973). The Process of Causal Attribution. American Psychologist, 28, 107-128.

Kim, W.C., \& Mauborgne, R. (1997). Fair Process: Managing in the Knowledge Economy. Harvard Business Review, 75(4), 65-75.

Klein, K.J., \& Sorra, J.S. (1996). The Challenge of Innovation Implementation. Academy of Management Review, 21, 1055-1080.

Kopelman, R.E., Brief, A.P., \& Guzzo, R.A. (1990). The Role of Climate and Culture in Productivity. In B. Schneider (Ed.) Organizational Climate and Culture, (pp. 282-318). San Francisco: Jossey-Bass.

Legge, K. (1995). Human Resource Management. Rhetorics and Realities. London: MacMillan Press.

Lewin, K. (1951). Field Theory in Social Science. New York: Harper and Brothers.

Li, X., Frenkel, S.J., \& Sanders, K. (2011). Strategic HRM as Process: How HR System and Organizational Climate Strength Influence Chinese Employee Attitudes. The International Journal of Human Resource Management, 22, 1825-1842.

Maitlis, S. (2005). The Social Processes of Organizational Sensemaking. Academy of Management Journal, 48, 21-49.

Miles, R.E., \& Snow, C.C. (1984). Designing Strategic Human Resource Systems. Organizational Dynamics, 13(1), 36-52.

Mischel, W. (1973). Toward a Cognitive Social Learning Conceptualization of Personality. Psychological Review, $80,252-283$.

Moorman, R. H. (1991). Relationship Between Organizational Justice and Organizational Citizenship Behavior: Do Fairness Perceptions Influence Employee Citizenship? Journal of Applied Psychology, 76, 845-855.

Moorman, R.H., \& Blakely, G.L. (1995). Individualism - Collectivism as an Individual Difference Predictor of Organizational Citizenship Behavior. Journal of Organizational Behavior, 16(2), 127-142. 
Nishii, L.H., \& Wright, P.M. (2007). Variability Within Organizations: Implications for Strategic Human Resource Management. Working Paper 07-02.CAHRS, Cornell University.

Paauwe, J., \& Boselie, P. (2005). HRM and Performance: What's Next? Working Paper 05-09. CAHRS, Cornell University.

Pereira, C.M.M., \& Gomes, J.F.S. (2012). The Strength of Human Resource Practices and Transformational Leadership: Impact on Organisational Performance. The International Journal of Human Resource Management, 23, 4301-4318.

Rousseau, D.M., Ho, V.T., \& Greenberg, J (2006). I-Deals: Idiosyncratic Terms in Employment Relationships. Academy of Management Review, 31, 977-994.

Rousseau, D.M., \& Wade-Benzoni, K.A. (1994). Linking Strategy and Human Resource Practices: How Employee and Customer Contracts are Created. Human Resource Management, 33, 463-489.

Schneider, B. (1990). The Climate for Service: An Application of the Climate Construct. In B. Schneider (Ed.) Organizational Climate and Culture, (pp. 383-412). San Francisco: Jossey-Bass.

Schuler, R.S., \& Jackson, S.E. (1987).Linking Competitive Strategies with Human Resource Management Practices. Academy of Management Executive, 1, 207-219.

Spreitzer, G.M. (1995). Psychological Empowerment in the Workplace: Dimensions, Measurement and Validation. Academy of Management Journal, 38, 1442-1465.

Truss, C. (2001). Complexities and Controversies in Linking Human Resource Management and Organizational Performance. Journal of Management Studies, 38, 1121-1149.

Ulrich, D., \& Lake, D. (1991). Organizational Capability: Creating Competitive Advantage. Academy of Management Executive, 5(1), 77-92.

Vroom, V. (1964). Work and Motivation. New York: Wiley.

Wright, P.M., \& McMahan, G.C. (1992). Theoretical Perspectives for Strategic Human Resource Management. Journal of Management, 18, 295-320.

Wright, P.M., McMahan, G.C., \& McWilliams, A. (1994). Human Resources and Sustained Competitive Advantage: A Resource-Based Perspective. International Journal of Human Resource Management, 5, 301-326.

Wright, P.M., \& Snell, S. A. (1991). Toward an Integrative View of Strategic Human Resource Management. Human Resource Management Review, 1, 203-225.

Wright, P.M., \& Snell, S.A. (1998). Toward a Unifying Framework for Exploring Fit and Flexibility in Strategic Human Resource Management. Academy of Management Review, 23, 756-772.

Wright, P. M., Dunford, B. B., \& Snell, S. A. (2001). Human Resources and the Resource Based View of the Firm. Journal of Management, 27, 701-721. 